\title{
Studies on the equine placenta II. Ultrastructure of the placental barrier
}

\author{
Carole A. Samuel, W. R. Allen* and D. H. Steven \\ Department of Anatomy, University of Cambridge, Downing Street, Cambridge CB2 3DY, and \\ *Agricultural Research Council, Animal Research Station, 307 Huntingdon Road,
}

Cambridge CB3 OJQ, U.K.

\begin{abstract}
Summary. In early pregnancy the equine placenta consists of a simple apposition of fetal and maternal epithelia, but it becomes more complex with the formation of microcotyledons between 75 and 100 days of gestation. Although the placental barrier maintains an epitheliochorial arrangement throughout the course of pregnancy, a thinning of the maternal epithelium and a progressive indentation of the chorionic epithelium by fetal capillaries shortens the length of the diffusion pathway and reduces the amount of placental tissue between fetal and maternal bloodstreams. These structural modifications may reflect the changing requirements of the fetus for $\mathrm{O}_{2}$ and other metabolites as gestation proceeds.

During the first $\mathbf{2 0 0}$ days of pregnancy there is evidence of intense pinocytotic activity by the cells of the trophoblast. From the 100th day of pregnancy there is a pronounced development of smooth endoplasmic reticulum, while rough endoplasmic reticulum and irregular, dense, membrane-bound bodies are a prominent feature of the paranuclear cytoplasm from Day 200. These changes suggest that the cells of the trophoblast become more highly involved in synthetic processes with increasing gestational age.
\end{abstract}

\section{Introduction}

The historical background to the study of the equine placenta has been summarized by Steven (1975) and Steven \& Samuel (1975). The events of early pregnancy have been described by Ewart (1897), van Niekerk (1965), van Niekerk \& Allen (1975), Marrable \& Flood (1975) and Douglas \& Ginther (1975). Studies of the development and fate of the endometrial cups have been made by Cole \& Goss (1943), Amoroso (1952), Allen, Hamilton \& Moor (1973) and Hamilton, Allen \& Moor (1973). King (1967) and Dickerson, Southgate \& King (1967) gave a detailed account of the origin and development of hippomanes in the horse and zebra, while other accessory structures have been described by Clegg, Boda \& Cole (1954) and Whitwell \& Jeffcott (1975). The term microcotyledon was first applied to the exchange units of the equine placenta by Drieux \& Thiery (1949). Samuel, Allen \& Steven (1974) described the development of the microcotyledons in early pregnancy, and the vascular arrangements within these structures were investigated by Tsutsumi (1962), with supplementary observations by Steven (1968) and Silver \& Steven (1975). The morphology and morphometry of the fetal membranes at term have been recorded by Prickett (1970) and Whitwell \& Jeffcott (1975).

The most comprehensive account of the histology of the equine placenta is that of Amoroso (1952), who collated the results of earlier authors with his own original observations but pointed out the need for consecutive and accurately dated placental material to cover the whole course of pregnancy. The ultrastructural features of the equine placenta have previously been described in a limited number of animals at known gestational ages (Silver, Steven \& Comline, 1973; Samuel et al., 1974; Steven \& Samuel, 1975), and also in undated specimens (Björkman, 1964, 1970, 1973; Wynn, 1967). From Amoroso's histological study we have proceeded to a more detailed investigation of the ultrastructural characteristics of the equine placental barrier. A preliminary report of this work has appeared elsewhere (Samuel et al., 1975). 


\section{Materials and Methods}

Samples of placenta were obtained from Welsh Mountain Pony mares at 46, 61, 75, 98, 101, 150, 200,250 and 300 days of gestation and prepared for electron microscopy by the method described previously (Samuel et al., 1974). Specimens were examined with a Philips 300 or AEI 6B electron microscope.

\section{Observations}

\section{Early pregnancy: Days 46, 61 and 75 (see Text-fig. 1a)}

By Day 46 attachment has been established between the uterine epithelium and a wide band of trophoblast in the equatorial region of the chorionic sac (van Niekerk \& Allen, 1975). The trophoblast at this time is a tall columnar epithelium supported by a basal lamina supplemented with moderate amounts of collagen. The cells are closely apposed at their lateral borders with specialised regions of attachment consisting of a zonula occludens (tight junction), zonula adhaerens (intermediate junction) and macula adhaerens (desmosome), collectively known as a junctional complex (Farquhar \& Palade, 1963) and localized at the apex of the epithelium (Pl. 2, Fig. 6). Desmosomes are located at intervals along the lateral cell walls which ares mooth for most of their length, but become slightly convoluted towards the base of the cells. The apical surface of the cells is generally invested by long thin microvilli which interdigitate at irregular intervals with those of the maternal epithelium. The fetal microvilli are often bunched together in groups, for they considerably outnumber their maternal counterparts. They are usually straight in appearance, but short, branched or crooked microvilli may be found occasionally.

The large nuclei of the trophoblast lie in the basal cytoplasm and have an irregular or lobulate appearance. The chromatin is evenly dispersed except for a thin layer condensed around the inner surface of the nuclear membrane. There is usually one small nucleolus. Parallel arrays of rough endoplasmic reticulum are found close to the nucleus and much of the apical cytoplasm is occupied by vermiform mitochondria with lamellar cristae. Immediately below the microvilli is a zone of cytoplasm packed with small pinocytotic vesicles varying in size from 50 to $100 \mathrm{~nm}$ but free from larger organelles (PI. 1, Fig. 1). Some of these vesicles are clear, some contain an electron-dense flocculent material, and others have fine electron-dense granules around the inner surface of the membrane. A few small electron-dense membrane-bound bodies are found scattered through the cytoplasm of the trophoblast, as are occasional microbodies, multivesicular bodies, microfibrils and microtubules.

The fetal blood vessels which are surrounded by a well-defined basal lamina, have a moderately electron-dense endothelium with a few luminal projections. At this early stage of gestation the vessels are clearly separated from the basal lamina of the trophoblast by the surrounding connective tissue (P1. 1, Fig. 1).

The maternal epithelium at the time of initial attachment consists of cuboidal cells resting upon a diffuse basal lamina. The cells are held together at their apices by junctional complexes and slight convolutions appear in the lateral walls. The cytoplasm of the maternal cells is more electron-dense than that of the fetal cells because the cytoplasmic granules are more closely packed. Microvilli occur at intervals along the apical surface of the cells, but, in contrast to the fetal side, no zone of organelle-free cytoplasm lies beneath them. The maternal microvilli are often branched at their origin or arise in clusters from a protrusion of the cell surface.

The nuclei of the maternal cells are spheroidal in shape with a slightly granular chromatin. Mitochondria are distributed throughout the cells and are generally spheroidal with lamellar cristae. Patches of rough endoplasmic reticulum and occasional Golgi vesicles are also present. Mediumsized electron-dense droplets, of ten with a halo between the contents and the membrane, are especially prominent in the maternal cells close to the microvillous surface (Pl. 1, Fig. 1). By specific staining with phosphotungstic and chromic acids (see Rambourg, 1967), we have shown that these droplets contain mucopolysaccharide. 


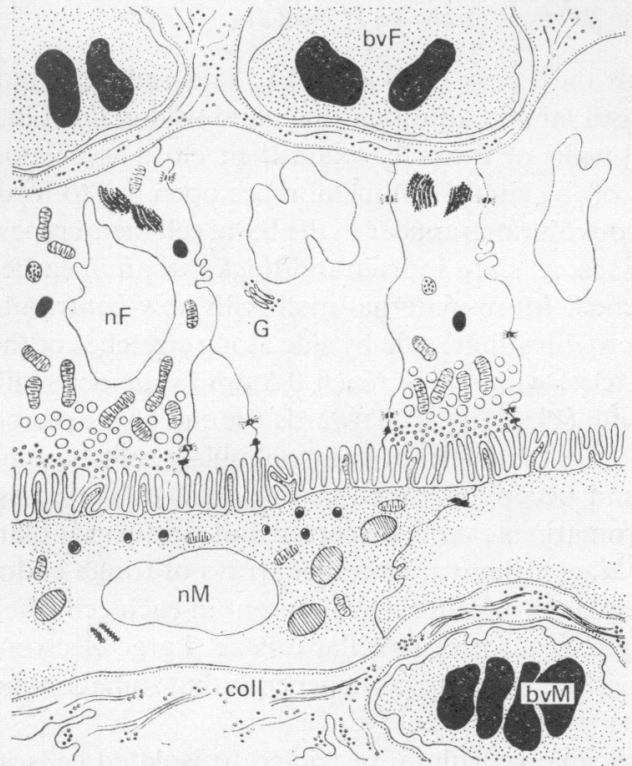

(a)

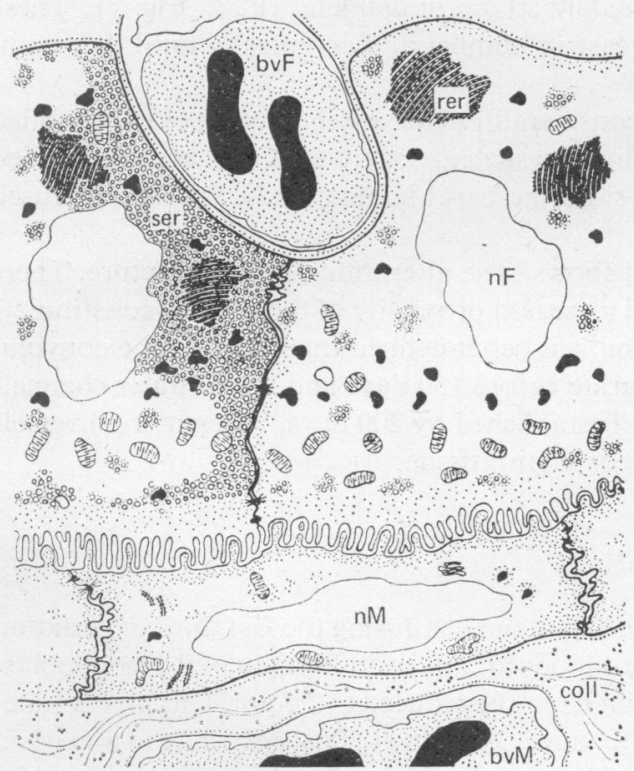

(c)

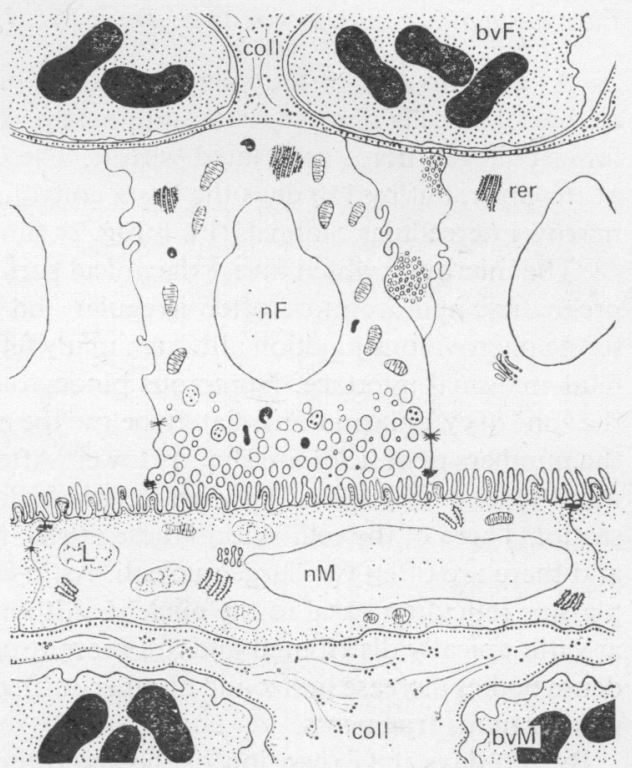

(b)

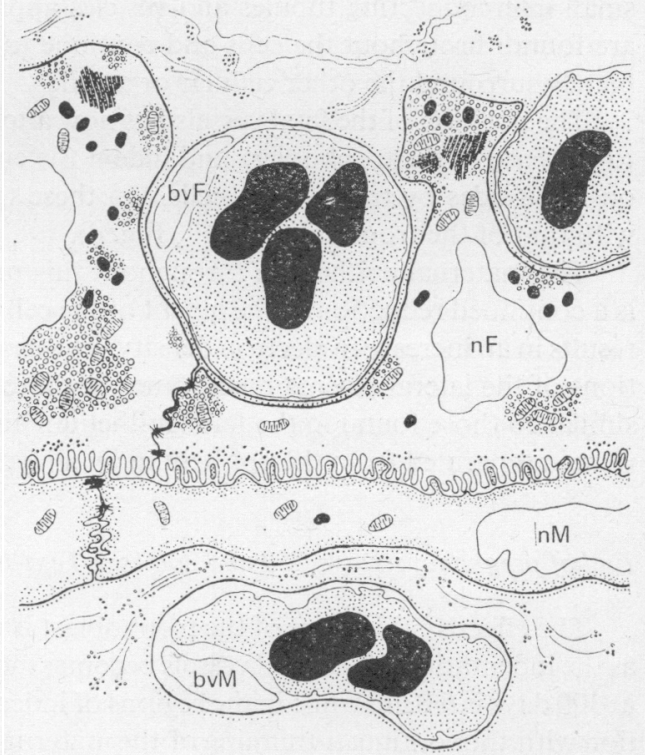

(d)

Text-fig 1. Generalized diagrams of the ultrastructural features of the equine placental barrier at consecutive stages of pregnancy. (a) 60 days; (b) 75-100 days; (c) 150-200 days; (d) 250-300 days. bvF, fetal blood vessel; bvM, maternal blood vessel; coll, collagen; G, Golgi apparatus; L, lipid; $n F$, fetal nucleus; nM, maternal nucleus; rer, rough endoplasmic reticulum; ser, smooth endoplasmic reticulum.

The maternal vessels, like those of the fetal side, have a moderately thick electron-dense endothelium with an irregular luminal surface. Each vessel is surrounded by a well-defined basal lamina. A wide band of connective tissue containing collagen and fibrocytes separates the maternal vessels from the base of the epithelium. 
Formation of the microcotyledons: Days 101, 150 and 200 (see Text-figs 16 and $1 c$ )

As development of the microcotyledons proceeds the trophoblast is seen to undergo a gradual change. The cells become reduced in height. The basal lamina although thick and well-defined has fewer collagen fibres associated with it. The lateral walls of the cells retain their close associaion at the apex, but by 150 days the basal convolutions of the lateral cell membranes open out to form narrow intercellular channels (Pl. 1, Fig. 2). Similar convolutions appear in the basal cell membranes.

The microvilli which invest the apical surface of the cells are shorter and thicker than in earlier pregnancy, and are more often irregular and branched. More maternal microvilli now contribute to the microvillous junction although many fetal microvilli still lie side by side along stretches of the fetal-maternal interface. Numerous pinocytotic vesicles, which may reach $0.5 \mu \mathrm{m}$ in diameter, fill the zone of cytoplasm immediately below the microvilli (Pl. 1, Fig. 3). Towards the end of the period the numbers of vesicles are slightly lower. After 101 days the nuclei of the trophoblast cells become more regular in outline; they are relatively large and occupy as much as one-third of the crosssectional area of the cell. Within these nuclei the chromatin is evenly dispersed and lightly granular, and there are often two large nucleoli. As in earlier stages, there are parallel arrays of rough endoplasmic reticulum basal to the nucleus. Although fewer mitochondria are present in each cell, they are still apically distributed and are more usually spheroidal with lamellar cristae. Large electrondense bodies increase in sizeand number during this period; most are homogeneous, but some contain membranous fragments.

By 200 days the expansion of the smooth endoplasmic reticulum, restricted to isolated cells at earlier stages, has spread to most of the trophoblast cells. The reticulum consists of a network of small interconnecting tubules and vesicles approximately $50 \mathrm{~nm}$ in diameter (Pl. 2, Fig. 7). These are found throughout the cells and continue to increase in number and complexity until they completely surround the other cellular organelles.

The position of the fetal vessels has now altered considerably. The vessels become closely applied to the base of the trophoblast and indent the epithelium to such an extent that they are surrounded on three sides by trophoblast cells. On these three sides the basal lamina of the capillary is fused with that of the trophoblast (Pl. 1, Fig. 4).

The maternal epithelium throughout this period shows little alteration in ultrastructure. There is a continued reduction in the height of the cells and increased proximity of the cellular constituents results in an increase in electron density. The basal lamina is better defined than before. The convolutions of the lateral plasma membranes begin to separate before 150 days and intercellular channels similar to those found in the fetal epithelium are well established by 200 days. The maternal vessels remain separated from the epithelium by a layer of connective tissue.

\section{End of pregnancy: Days 250 and 300 (see Text-fig. 1d)}

The effective thickness of the trophoblast is reduced still further during the last third of gestation as the indentation of the fetal vessels becomes more pronounced. The overall height of the trophoblast at 300 days is $6.0 \mu \mathrm{m}$ while in the regions of indentation it may be reduced to $2.5 \mu \mathrm{m}$. This, in conjunction with the continued thinning of the maternal epithelium, $3.25 \mu \mathrm{m}$ at 300 days, leads to a marked reduction in the transplacental intervascular distance. The nuclei and mitochondria of the trophoblast are generally confined to those parts of the cells lateral to the indented blood vessels; in the subvascular region between the indented capillaries and the microvillous junction there are few organelles (Pl. 2 , Fig. 5). The microvilli are reduced in height along the fetal-maternal interface. Pinocytotic vesicles, present in the zone of cytoplasm immediately below the microvilli, are the only structures consistently present in the subvascular regions.

The trophoblast cells are packed with small tubules and vesicles of smooth endoplasmic reticulum, interspersed at intervals with arrays of rough endoplasmic reticulum. There are some lipid droplets in the trophoblast and crystalline inclusions are occasionally seen. The most noticeable development in the trophoblast during the last third of gestation is the formation of large numbers of electrondense bodies. Like those seen at earlier stages of gestation, these bodies vary in size and shape and 

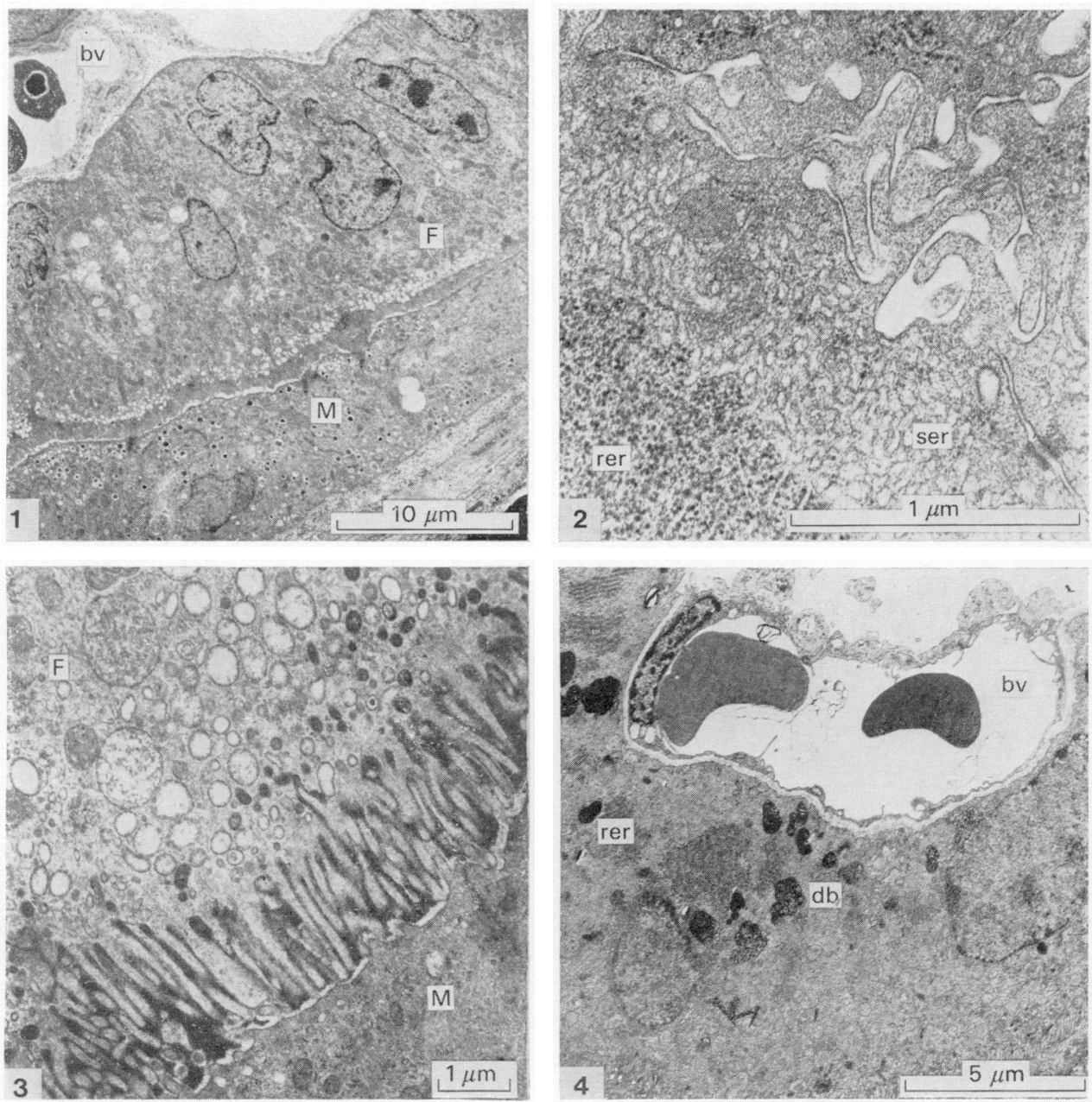

Fig. 1. Low-power electron micrograph of the equine placenta at 45 days of gestation. At this stage the nuclei of the fetal epithelium are highly irregular in outline and pinocytotic vesicles are found in the apical region of the cytoplasm (see Text-fig. la). bv, fetal blood vessel; F, fetal epithelium; M, maternal epithelium.

Fig. 2. Intercellular channel in the basal region of the trophoblast at 200 days of gestation. rer, rough endoplasmic reticulum; ser, smooth endoplasmic reticulum.

Fig. 3. Microvillous junctional zone of the equine placenta at 101 days of gestation. Numerous pinocytotic vesicles fill the apical cytoplasm of the fetal epithelium. Some of the vesicles appear to contain the electrondense anterial similar to that seen in the uterine lumen. F, fetal epithelium; M, maternal epithelium.

Fig. 4. Intraepithelial fetal capillary at 200 days of gestation. The basal laminae of trophoblast and fetal capillary are no longer separated by connective tissue, but have fused to form a single layer. Large electrondense bodies are now found towards the bases of the trophoblast ceils. bv, fetal capillary: db, electrondense body: rer, rough endoplasmic reticulum. 
PLATE 2
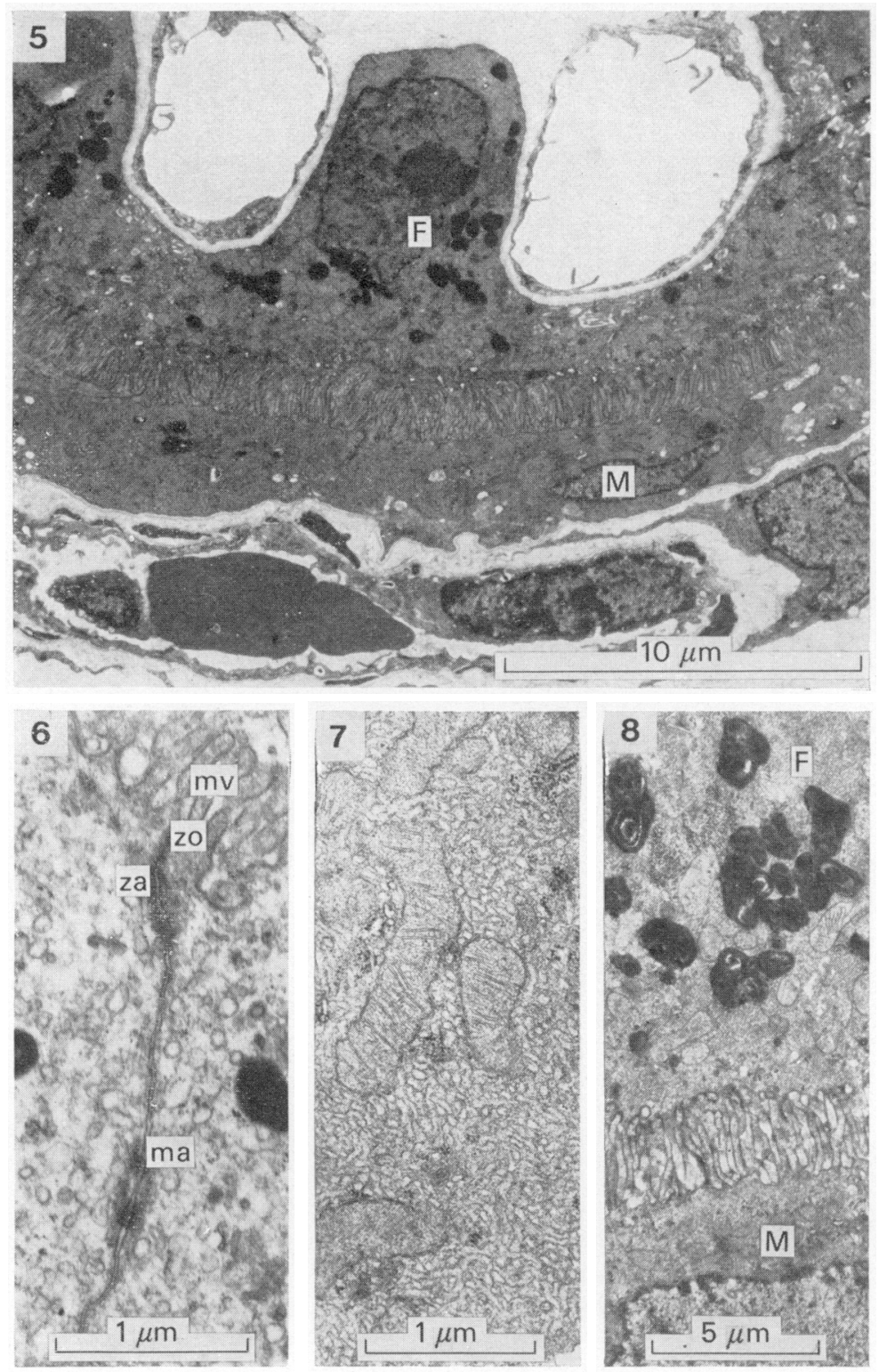

Fig. 5. Low-power electron micrograph of the equine placenta at 300 days of gestation. The nuclei and most of the mitochondria of the trophoblast are confined to parts of the cells lateral to the indented fetal blood vessels. Between the capillaries and the microvillous junction there are few organelles (see Text-fig. 1). F. fetal side of placenta: $M$, maternal side of placenta.

Fig. 6. Apical region of trophoblast at 98 days of pregnancy to show a junctional complex between lateral cell membranes. ma, macula adhaerens (desmosome): mv, microvilli: za, zonula adhaerens (intermediate junction); 20 , zonula occludens (tight junction).

Fig. 7. Smooth endoplasmic reticulum and mitochondria in the trophoblast at 200 days of gestation.

Fig. 8. Electron-dense bodies in the apical cytoplasm of the trophoblast at 300 days of gestation. F. fetal epithelium: M, maternal epithelium. 
many contain membranous fragments (Pl. 2, Fig. 8). Although they may be randomly distributed when present in large numbers they are more usually aggregated in zones immediately apical to and parallel with the nucleus. Intercellular channels are still present although less wide than formerly.

The maternal epithelium at this time is extremely attenuated and contains few organelles. Most of the mitochondria are large and irregular although in some cells they are smooth with tubular cristae. At 300 days cells have been observed in which a development of the Golgi apparatus is associated with the larger mitochondria. Short isolated lengths of rough endoplasmic reticulum are visible in these same cells. The maternal nuclei are generally irregular and often pyknotic in appearance; the chromatin is considerably condensed and the nuclear envelope shrunken. Degenerative changes are greatest in those regions of the microcotyledon which show complicated folding, but are less common towards the edges of the microcotyledons.

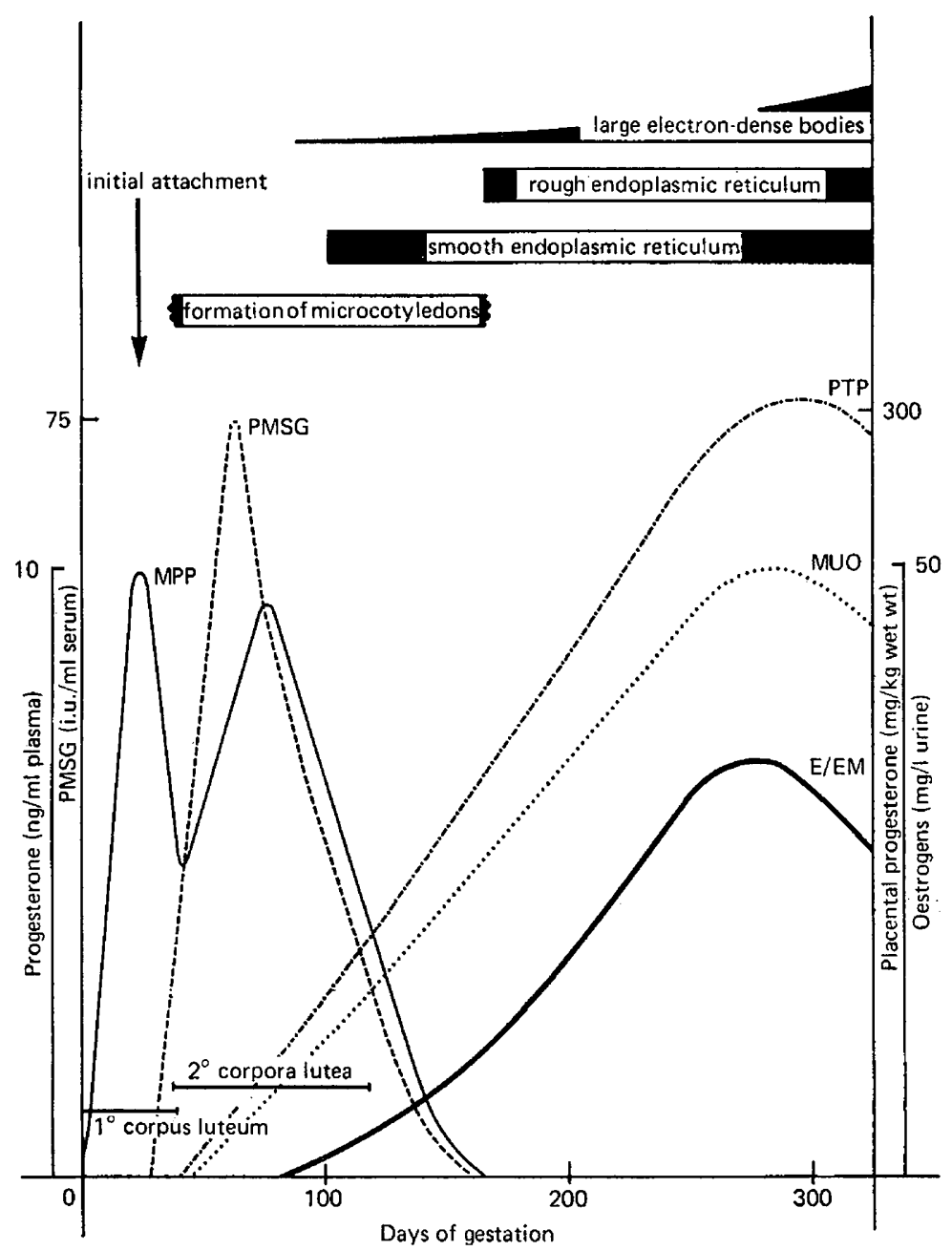

Text-fig 2. Representation of endocrine events during pregnancy in the mare and concurrent developments in the structure of the trophoblast. E/EM, equilin and equilenin in maternal plasma; MPP, maternal plasma progestagens; MUO, maternal urinary oestrogens; PMSG, pregnant mares' serum gonadotrophin; PTP, placental progestagens. For original work see Rowlands, Allen \& Rossdale (1975). 


\section{Discussion}

Fetal and maternal bloodstreams in placental mammals are separated by a highly specialized structure known as the placental barrier, which is formed, according to species, by various degrees of interaction between fetal and maternal tissues. Except in the region of the endometrial cups, where the uterus is invaded by the cells of the chorionic girdle (Allen et al., 1973), the placental barrier of the mare remains epitheliochorial in arrangement throughout the course of pregnancy. After the 75th day of gestation the placental barrier is confined to the villi and crypts of the developing microcotyledons (Drieux \& Thiery, 1949; Samuel et al., 1974). Elsewhere the chorion is separated from the endometrium by the products of glandular secretions (Steven \& Samuel, 1975).

The changes which occur during the course of pregnancy are most prominent on the fetal side of the barrier. The intense pinocytotic activity of the first 200 days of pregnancy suggests that during this period the cells of the trophoblast are engaged in the uptake of fluid from the narrow space separating fetal and maternal interdigitating microvilli. From the 100th day of pregnancy there is a pronounced development of smooth endoplasmic reticulum, while parallel arrays of rough endoplasmic reticulum and irregular dense membrane-bound inclusions become prominent in the paranuclear cytoplasm from the 200th day. These changes suggest that the cells of the trophoblast become more highly involved in synthetic processes as gestation proceeds. Flood \& Marrable (1973, 1975) have detected hydroxysteroid dehydrogenase enzymes in the trophoblast of the equine placenta with the most intense activity corresponding to the period of development of the smooth endoplasmic reticulum. Our observations support the conclusion of Flood \& Marrable (1975) that the equine trophoblast has a major role in steroid interconversions. In Text-fig. 2 the hormonal events of pregnancy are compared with the changing subcellular constituents of the tissues of the trophoblast, in the hope of stimulating further study and discussion.

The most noticeable alteration on the maternal side of the placenta is a thinning of the uterine epithelium, which is reduced to one-third of its original height by the 300th day of pregnancy (see Samuel et al., 1975). A concurrent indentation of the trophoblast by the capillaries of the umbilical circulation not only shortens the total distance between fetal and maternal bloodstreams, but also reduces the proportion of actively respiring placental tissue along the diffusion pathway (Text-fig. 3 ). In early pregnancy fetus and placenta are effectively in series, for fetal and maternal bloodstreams are

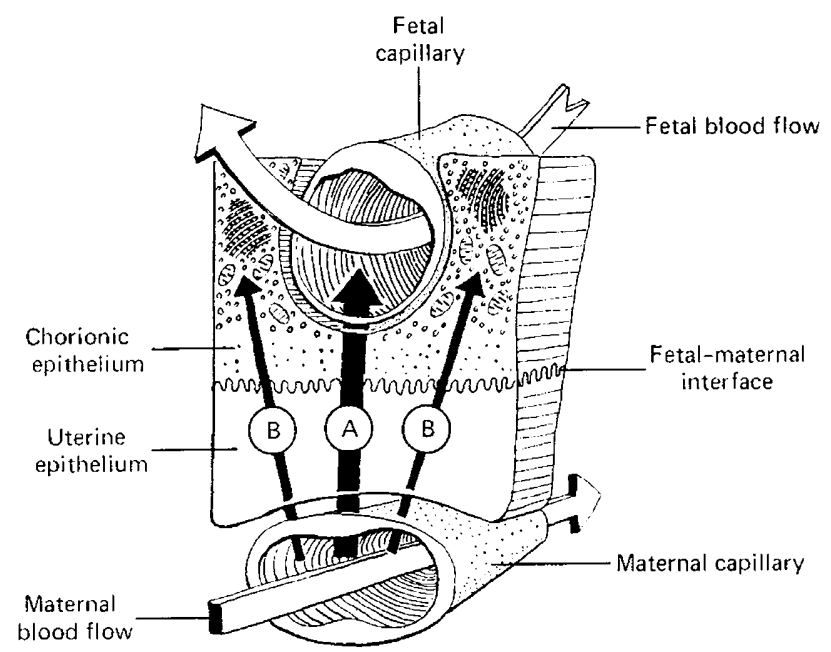

Text-fig 3. Diagrammatic representation of diffusion pathways across the placenta of the mare in the last 3 months of gestation. Since most of the fetal organelles are situated in the part of the cytoplasm which is lateral to the fetal capillary, $\mathrm{O}_{2}$ may be transferred to fetal blood with minimal uptake by intervening tissue. (A) direct pathway from maternal to fetal capillary; (B) parallel pathways to fetal placental tissue. 
separated by the full thickness of the chorionic and uterine epithelia. With this arrangement it would seem that metabolites in transit from the maternal to the fetal circulation cannot avoid passage through actively respiring placental tissues. The relationships of later pregnancy, in which fetus and placenta are disposed much more in parallel, may thus reflect the increasing metabolic requirements of the fetus as gestation proceeds.

This work was supported by the Thoroughbred Breeders Association and the Medical and Agricultural Research Councils. We are most grateful to Mr L. E. A. Rowson, F.R.S., for assistance with the surgery; to the staff of the A.R.C. Unit of Reproductive Physiology and Biochemistry, and the Department of Anatomy, University of Cambridge. C.A.S. is supported by the Wellcome Trust.

\section{References}

Allen, W.R., Hamilton, D.W. \& Moor, R.M. (1973) The origin of the equine endometrial cups. II. Invasion of the endometrium by trophoblast. Anat. Rec. 177, 485-501.

Amoroso, E.C. (1952) Placentation. In Marshall's Physiology of Reproduction, Vol. 2, pp. 127-311. Ed. A.S. Parkes. Longmans Green, London.

BJÖRKMAN, N. (1964) Ultrastructural features of placentae in ungulates. Proc. 5th Int. Congr. Anim. Reprod. \& A.I., Trento, pp. 260-263.

Björkman, N. (1970) An Atlas of Placental Fine Structure. Baillière Tindall \& Cassell, London.

Björkman, N. (1973) Fine structure of the fetal-maternal area of exchange in the epitheliochorial and endotheliochorial types of placentation. Acta anat. 86, Suppi. 1, 1-22.

Clegg, M.T., Boda, J.M. \& Cole, H.H. (1954) The endometrial cups and allantochorionic pouches in the mare with emphasis on the source of equine gonadotrophin. Endocrinology 54, 448-463.

Cole, H.H. \& Goss, H. (1943) The source of equine gonadotropin. In Essays in Biology in Honor of Herbert M. Evans, pp. 105-119. University of California Press, Berkeley.

Dickerson, J.W.T., Southgate, D.A.T. \& King, J.M. (1967) The origin and development of the hippomanes in the horse and zebra. 2. The chemical composition of the foetal fluids and hippomanes. J. Anat. 101, 285-293.

Douglas, R.H. \& GinTHER, O.J. (1975) Development of the equine fetus and placenta. J. Reprod. Fert., Suppl. 23, 503-505.

DrieUX, H. \& ThIERY, G. (1949) Placentation chez les mammifères domestiques. Placenta des équidés. Recl. Méd. vét. Éc. Alfort 125, 197-214.

EWART, J.C. (1897) A Critical Period in the Development of the Horse. A. \& C. Black, Edinburgh.

FARQuhar, M.G. \& PAlade, G.E. (1963) Junctional complexes in various epithelia. J. Cell Biol. 17, 341375.

Flood, P.F. \& Marrable, A.W. (1973) Steroid metabolism in the feto-placental unit of the mare: a histochemical study during mid-gestation. J. Reprod. Fert. 35, 617-618.

Flood, P.F. \& Marrable, A.W. (1975) A histochemical study of steroid metabolism in the equine fetus and placenta. J. Reprod. Fert., Suppl. 23, 569-573.

Hamilton, D.W., Allen, W.R. \& Moor, R.M. (1973)
The origin of the equine endometrial cups. III. Light and electron-microscopical study of fully developed equine endometrial cups. Anat. Rec. 177, 503-518.

KING, J.M. (1967) The origin and development of the hippomanes in the horse and zebra. 1. The location, morphology and histology of the hippomanes. J. Anat. 101, 227-284.

Marrable, A.W. \& Flood, P.F. (1975) Embryological studies on the Dartmoor Pony during the first third of gestation. J. Reprod. Fert., Suppl. 23, 499-502.

Pricketr, M.E. (1970) Abortion and placental lesions in the mare. J. Am. vet. med. Ass. 157, 1465-1470.

Rambourg, A. (1967) Détection des glycoprotéins en microscopie électronique: coloration de la surface cellulaire et de l'appareil de Golgi par un mélange acide chromique-phosphotungstique. C. r. hebd. Séanc. Acad. Sci., Paris 265, 1426-28.

Rowlands, I.W., Allen, W.R. \& Rossdale, P.D. (Eds) (1975) Equine Reproduction. J. Reprod. Fert., Suppl. 23.

Samuel, C.A., Allen, W.R. \& Steven, D.H. (1974) Studies on the equine placenta. I. Development of the microcotyledons. J. Reprod. Fert. 44, 441-445.

Samuel, C.A., Allen, W.R. \& Steven, D.H. (1975) Ultrastructural development of the equine placenta. J. Reprod. Fert., Suppl. 23, 575-578.

Silver, M. \& Steven, D.H. (1975) Placental exchange of blood gases. In Comparative Placentation, pp. 161-188. Ed. D.H. Steven. Academic Press, London.

Silver, M., Steven, D.H. \& Comline, R.S. (1973) Placental exchange and morphology in ruminants and the mare. In Foetal and Neonatal Physiology, pp. 245-271. Eds R.S. Comline, K.W. Cross, G.S. Dawes \& P.W. Nathanielsz. Cambridge University Press.

SteVEN, D.H. (1968) Structural differences between exchange units in the sheep and horse placenta. $J$. Physiol., Lond. 196, 24P-26P.

Steven, D.H. (1975) Anatomy of the placental barrier. In Comparative Placentation, pp. 25-57. Ed. D.H. Steven. Academic Press, London.

Steven, D.H. \& Samuel, C.A. (1975) Anatomy of the placental barrier in the mare. J. Reprod. Fert., Suppl. 23, 579-582.

TsuTsumI, Y. (1962) The vascular patterns of the placenta in farm animals. J. Fac. Agr. Hokkaido (imp.) Univ. 52, 372-482.

VAN NIEKERK, C.H. (1965) The early diagnosis of 
pregnancy, the development of the foetal membranes and nidation in the mare. J. S. Afr. vet. med. Ass. $36,483-488$.

van Niekerk, C.H. \& Allen, W.R. (1975) Early embryonic development in the horse. $J$. Reprod. Fert., Suppl. 23, 495-498.
WhITwELL, K.E. \& JBFFCOTT, L.B. (1975) Morphological studies on the fetal membranes of the horse at term. Res. oet. Sci. 19, 44-55.

WYNN, R.M. (1967) Comparative electronmicroscopy of the placental junctional zone. Obstet. Gynec. 29, $644-661$.

Received 11 February 1976 